\title{
Influence of Maternal BMI and Maternal Weight Gain during Pregnancy on Maternal and Perinatal Outcome - A Retrospective Data Analysis of Pregnancies during 2004 and 2014
}

Kundu S*, Kaukemueller L, von Kaisenberg C, Hillemanns P, Soergel P, Kuehnle E and Staboulidou I

Department of Gynaecology and Obstetrics, Hannover Medical School, Germany

*Corresponding author: Dr. Sudip Kundu, Department of Obstetrics and Gynaecology, Hannover Medical School, Carl-Neuberg-Str. 1, 30625 Hannover, Germany

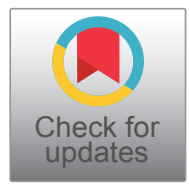

\begin{abstract}
Introduction: The aim of this study was to describe the influence of maternal pregnancy body mass index (BMI) and maternal weight gain during pregnancy on perinatal and neonatal outcomes.

Methods: Retrospective analysis of singleton pregnancies $>37$ weeks of gestation delivered between 2004 and 2014. Fetal anomalies and intrauterine deaths have been excluded.

Results: Our data demonstrate a correlation between prepregnancy BMI and preeclampsia $\left(k^{*}=0.029, p=0.024\right)$ as well as between the $\mathrm{BMI}$ at the time of delivery and maternal hypertension $\left(k^{*}=0.443, p=0.046\right)$ and preeclampsia $\left(k^{*}=\right.$ $0.491, p=0.02)$. The results also show a significant relation between maternal BMI and the birth mode $\left(k^{*}=0.052, p=\right.$ $0.0003)$ and between BMI and fetal macrosomia $(r=0.009$, $p=0.03$ ). The rate of macrosomic newborns was higher both in obese women $(r=0.165, p=0.016)$ as well as in underweight women $(r=0.196, p=0.036)$. Weight gain during pregnancy seems to play a minor role compared to the pre-pregnancy $\mathrm{BMI}$ and the maternal $\mathrm{BMI}$ at the time of delivery.

Conclusion: Optimal weight gain during pregnancy in relation to maternal pre-pregnancy BMI remains a controversial issue in perinatology and pregnancy management. Overweight and obese women have an increased risk of preeclampsia, hypertension and macrosomia. Underweight women are also at risk of adverse perinatal outcome.
\end{abstract}

\section{Keywords}

High risk pregnancy, Obesity, Perinatal complications

\section{Introduction}

For the last two decades, obesity rates have increased in both developed and developing countries and, in particular, the number of obese women has roughly doubled during this period [1].

$35.5 \%$ of the female population living in the United States are obese, as defined by a Body Mass Index (BMI) of $\geq 30$ and $68 \%$ are overweight as defined by a BMI of $\geq 25$, whereas $41.4 \%$ of the German population are classified as overweight or obese $(60.1 \%$ of the male and $42.9 \%$ of the female population) [2]. In Australia, nearly one-third of all pregnant women are overweight or obese [3]. Approximately $13.8 \%$ of the worldwide female population is declared as obese [4]. Current projections assume that in 2030 more than $50 \%$ of the European population will be obese [5]. Obesity used to be considered to be a problem in high-income countries once, but it is now recognized as one of the biggest epidemics including major public health issues of the $21^{\text {st }}$ century (with major public health issues) [6].

Pregnant women have a physiological weight gain which consists of $30 \%$ of fetus, $50 \%$ of tissue liquid, increased blood volume, breast tissue and fat depot and $20 \%$ of amniotic fluid and placenta [7]. A German study called KiGGS-study has evaluated the maternal weight gain in Germany for the last 20 years. This study demonstrated an average increase of maternal weight gain during pregnancy from 13 to $15 \mathrm{~kg}$ over the years [8].

Citation: Kundu S, Kaukemueller L, von Kaisenberg C, Hillemanns P, Soergel P, et al. (2019) Influence of Maternal BMI and Maternal Weight Gain during Pregnancy on Maternal and Perinatal Outcome A Retrospective Data Analysis of Pregnancies during 2004 and 2014. Int J Womens Health Wellness 5:095. doi.org/10.23937/2474-1353/1510095

Accepted: May 04, 2019: Published: May 06, 2019

Copyright: (c) 2019 Kundu S, et al. This is an open-access article distributed under the terms of the Creative Commons Attribution License, which permits unrestricted use, distribution, and reproduction in any medium, provided the original author and source are credited. 
Additionally, the number of obese women in the first trimester has increased. Various studies demonstrate a significant influence of maternal pre-pregnancy obesity and excess weight gain during pregnancy on obstetrical and neonatal outcome. Adverse obstetrical outcomes include induced preterm delivery, pre-eclampsia, gestational hypertension, gestational diabetes (GDM), type 2 diabetes, and cardiovascular diseases like venous thromboembolism [9-11] and an elevated risk of cesarean section [12]. Whereas regarding adverse neonatal outcome, a higher number of APGAR scores $<7$ and stillbirth [9], associated with the increase amount of macrosomic babies are seen. But a low pre-pregnancy weight is also associated with complications like preterm labour and neonatal underweight.

It is also known that children of women with GDM are more likely to be obese and have impaired glucose tolerance, metabolic syndrome and diabetes in childhood and adulthood $[13,14]$. One possible explanation of the above described relations might be the theory of perinatal programming, which means that in addition to the genetic disposition fundamental metabolic processes are determined during pregnancy [15].

In 2009 the Institute of Medicine (IOM) released new guidelines regarding appropriate maternal weight gain in pregnancy according to pre-pregnancy BMI, which have been widely adopted, but not generally accepted: underweight (BMI < 18.5) women should gain 12.5-18 $\mathrm{kg}$, normal weight (BMI 18.5-24.9) women $11.5-16 \mathrm{~kg}$, overweight (BMI 25-29.9) women 7-11.5 kg and obese $(\mathrm{BMI} \geq 30)$ women $5-9 \mathrm{~kg}[16,17]$.

The importance of weight gain during pregnancy remain sun clear as some studies report a relation between weight gain during pregnancy and the rate of obstetrical and delivery complications $[18,19]$ while others were able to demonstrate no connection between these factors [20].

However, the effect of pre-pregnancy BMI as well as the maternal weight gain during pregnancy with regard to the original weight before pregnancy on obstetrical, neonatal and delivery outcome is still discussed controversially in literature.

In reflection of the ongoing discussion this retrospective study was conducted to analyze the longitudinal development of maternal BMI and maternal weight gain during pregnancy in nulliparous and multiparous women during a time period from 2004 to 2014. Furthermore, the association of low, normal, and high BMI and maternal weight gain during pregnancy on maternal, neonatal and delivery outcome were investigated.

\section{Methods}

For this retrospective data analysis all patients with singleton pregnancy $>37$ gestational weeks, who delivered during the period from January 2004 to December
2014 at the department of obstetrics of the Medical School of Hannover, were included and selected from the obstetric database. Missing data was obtained from medical records. The data used for evaluation purposes were inserted in Excel and anonymized.

\section{Inclusion criteria}

All patients with a live-born singleton pregnancy $>37$ weeks of gestation without fetal malformations.

\section{Exclusion criteria}

Multiple pregnancies, intrauterine death, singleton pregnancies $<37$ weeks of gestation, fetal malformations.

\section{Maternal characteristics included}

Maternal age, gravidity, parity, gestational week at delivery, mode of delivery, indication for operative childbirth, BMI before pregnancy and at the time of delivery, weight gain during pregnancy, maternal diseases like diabetes mellitus, gestational diabetes, hypertension, pregnancy induced hypertension, preeclampsia, thrombophilia, hyper- and hypothyroidism.

\section{Neonatal characteristics included}

Birth weight (including birth percentile), birth length and head circumference at birth, APGAR score, arterial umbilical $\mathrm{pH}$, base excess, reason for transfer to neonatal intensive care unit (NICU).

Primary outcome parameters depending on prepregnancy $\mathrm{BMI}, \mathrm{BMI}$ at time of birth and weight gain are:

- Mode of delivery

- Rate of induction of labor

- Maternal diseases: Gestational diabetes and diabetes mellitus, hypertension, preeclampsia and HELLP, thrombophilia

- Maternal peripartal complications: Perineal/vaginal tears and injury, uterine rupture

- Neonatal outcome measures: $\mathrm{pH}$ value of arterial umbilical cord $<7.20$, Apgar score $5^{\prime}<7$, macrosomia as defined birth weight $4000 \mathrm{~g}$ and more or birth weight $>90$.centile, IUGR defined as birth weight $<$ 10.centile, shoulder dystocia, necessity for oxygenation, necessity for intubation, necessity for reanimation, necessity for transfer to NICU

\section{Statistical analysis}

The statistical analysis was conducted in cooperation with the Institute of Statistics of the Leibniz University Hanover using the statistics program R (http://www. cran.r-project.org).

First of all, a descriptive analysis of the study collective was performed. Second, a correlation analysis was executed regarding pregnancy complications, birth 
and neonatal complications in regard to maternal BMI and weight gain.

Statistical analysis was performed by linear regression analysis or logistic regression analysis depending on the variables. For nominal scaled variables, the corrected contingency coefficient was calculated as a measure of the relationship between the variables and tested for the independence of the parameters with the $\chi^{2}$ independence test. In ordinal scaled data the Spearman rank correlation coefficient was used. Also, logistic regression was calculated, and significance was tested by the t-test.

Statistical significance was achieved if $p<0.05$.

The study was approved by the regional Ethics Committee of Hanover (No 3166-2016).

\section{Results}

15439 pregnant women were included in this study. The demographic parameters are shown in Table 1. The mean maternal BMI before pregnancy was 24.73. The average increase of weight during pregnancy was $5 \mathrm{BMI}$ points $(13.9 \mathrm{~kg})$ with a mean maternal BMI of 29.74 at the time of birth. The highest increase of weight during pregnancy was $38 \mathrm{~kg}$, the highest weight loss was 17.5 $\mathrm{kg}$. The distribution of BMI is shown in Table 2.

\section{Mode of delivery}

The majority of the pregnant women (66.4\%) delivered between 38 to 41 weeks of gestation. $66 \%$ of the women delivered spontaneously, whereas an elective C-section was carried out in $13.6 \%$ (2098 cases), a second stage C-section was carried out in $11.5 \%$ (1777 cases) and $8.5 \%$ (1313 cases) of the women delivered via

Table 1: Demographic parameters of the whole study population.

\begin{tabular}{|l|l|}
\hline & Mean (Min.-Max.) \\
\hline Maternal Age (years) & $31.2(14.4-56.1)$ \\
\hline Gestational Age at delivery (weeks) & $40(37-42)$ \\
\hline Weight before pregnancy $(\mathrm{kg})$ & $69(30-196)$ \\
\hline BMl before pregnancy $\left(\mathrm{kg} / \mathrm{m}^{2}\right)$ & $24.7(12.8-62.5)$ \\
\hline Weight at delivery $(\mathrm{kg})$ & $82.8(38-220)$ \\
\hline BMl at delivery $\left(\mathrm{kg} / \mathrm{m}^{2}\right)$ & $29.6(16.8-62.5)$ \\
\hline Gestational weight gain $(\mathrm{kg})$ & $13.9(-17.5-38)$ \\
\hline
\end{tabular}

vaginal operative delivery.

An induction of labor was seen in $27.4 \%$ (4236 cases) of all cases. In the group of underweight pregnant women labor was induced in $20 \%$, while in the group of overweight women labor was induced in $40 \%$. Despite the higher rate of induction of labor in obese women compared to underweight women, these results are not statistically significant $(p=0.7)$.

Our results show a significant relation between the BMI and birth mode $\left(k^{*}=0.052, p=0.0003\right)$. There was a significant negative correlation between adipositas and elective C-section $\left(k^{*}=-0.031, p=0.0004\right)$, while there was no significant relation between adipositas and the rate of second stage $\mathrm{C}$-section. The results show that there was a lower rate of elective C-section in obese women.

There was a significant negative correlation between underweight and elective $\mathrm{C}$-section $\left(\mathrm{k}^{*}=-0.347, \mathrm{p}=\right.$ 0.001 ) and a positive correlation between underweight and second stage $C$-section $\left(k^{*}=0.293, p=0.002\right)$. These results demonstrate that underweight is associated with a higher rate of second stage c-sections, but a lower rate of elective c-section.

\section{Maternal disease and peripartal complications}

Maternal diseases like hypothyreosis, thrombophilia, gestational diabetes, diabetes mellitus, hypertension, preeclampsia and HELLP were approximately evenly distributed in all weight categories.

There was a significant correlation $\left(k^{*}=0.029, p=\right.$ 0.024 ) between pre-pregnancy-BMI and preeclampsia. A higher pre-pregnancy-BMI was associated with an increased risk to develop preeclampsia.

Additionally, there was a significant correlation between BMI at the time of delivery and maternal hypertension as well as preeclampsia. A higher BMI at the time of delivery was associated with an increased risk to develop maternal hypertension $\left(k^{*}=0.443, p=\right.$ $0.046)$ and preeclampsia $\left(k^{*}=0.491, p=0.02\right)$.

The weight gain during pregnancy showed no influence on maternal diseases.

With regard to the incidence of childbirth injury we found 1832 cases with a vaginal tear and 63 cases with a cervical tear without statistical significance between the

Table 2: Distribution of BMI, macrosomic and IUGR newborns with regard of the different maternal weight groups.

\begin{tabular}{|l|l|l|l|l|}
\hline $\begin{array}{l}\text { Maternal weight } \\
\text { group }\end{array}$ & $\begin{array}{l}\text { BMI before } \\
\text { pregnancy } \mathbf{n}(\%)\end{array}$ & $\begin{array}{l}\text { BMI at delivery } \\
\mathbf{n}(\%)\end{array}$ & $\begin{array}{l}\text { Macrosomic newborns } \mathbf{~ ( \% ) ~} \\
\text { corresponding to each weight } \\
\text { group }\end{array}$ & $\begin{array}{l}\text { IUGR newborns n (\%) } \\
\text { corresponding to each weight } \\
\text { group }\end{array}$ \\
\hline Total population & $\mathrm{n}=15439$ & $\mathrm{n}=15439$ & $2024(13.11 \%$ of total population) & $1258(5.58 \%$ of total population) \\
\hline Under weight & $1071(6.94 \%)$ & $10(0.06 \%)$ & $154(14.69 \%)$ & $70(6.68 \%)$ \\
\hline Normal weight & $8579(55.57 \%)$ & $2263(14.66 \%)$ & $1051(12.41 \%)$ & $713(8.42 \%)$ \\
\hline Overweight & $3632(23.52 \%)$ & $7117(46.10 \%)$ & $495(13.54 \%)$ & $287(7.85 \%)$ \\
\hline Obesity & $2157(13.97 \%)$ & $6049(39.18 \%)$ & $324(14.32 \%)$ & $188(8.31 \%)$ \\
\hline
\end{tabular}


different weight groups. 2031 perineal lacerations were noted. In those cases there was a significant positive correlation between pre-pregnancy-BMI as well as with $\mathrm{BMI}$ at the time of childbirth and the incidence of perineal lacerations $\left(k^{*}=0.010, p=0.02\right)$ meaning that a higher BMI leads to an increased risk for perineal lacerations.

The weight gain during pregnancy showed no significant influence.

Regarding the number of complications during childbirth there were 25 uterine ruptures $(0.16 \%)$ and 43 early abruptions of placenta $(0.28 \%)$. Although uterine rupture was at $0.31 \%$ higher in obese women, this did not reach statistical significance between. Although a positive correlation between weight gain during pregnancy and the risk of uterine rupture $\left(\mathrm{K}^{*}=0.056, \mathrm{p}=\right.$ $0.09)$ was visible, this was not significant.

\section{Neonatal outcome}

The mean weight of the newborn was $3500 \mathrm{~g}$, the mean length of the newborn was $52.5 \mathrm{~cm}$ and the mean head circumference was $35 \mathrm{~cm}$.

The mean birth $\mathrm{pH}$ was 7.3. The analysis demonstrated that the rate of complication with regard to a low $\mathrm{pH}<7.14$ increased with higher pre-pregnancy BMI $(r=$ $-0.017, p=0.021$ ) as well as with higher BMI at the time of delivery $(r=-0.014, p=0.071)$.

Considering the different BMI groups, the analysis revealed the higher rate of fetal acidosis $(\mathrm{pH}<7.14)$ in overweight $(r=-0.218, p=0.042)$ and obese women $(r$ $=-0.287, \mathrm{p}=0.02$ ).

901 (5.85\%) children had to be transferred to the intensive care unit and 860 (5.58\%) children needed oxygenation. $95(0.62 \%)$ children were intubated and reanimation was necessary in 316 (2.05\%) cases. The mean APGAR score after one minute was 9 and after 5 minutes 10 . However, there were no differences with regard to the weight groups.

1258 (8.15\%) newborns were IUGR and 2024 (13.11\%) newborns were macrosomic. Table 2 also displays the distribution of macrosomic and IUGR newborns with regard to the different weight groups at the time of delivery. There was a significant correlation ( $r$ $=0.009, p=0.03$ ) between BMI at the time of delivery and the occurrence of macrosomia. The rate of macrosomic newborns was higher in obese women $(r=0.165$, $p=0.016)$. Additionally, the results demonstrated that underweight women are also at a significantly increased risk of their newborns suffering from macrosomia $(r=$ 0.196, $p=0.036)$.

There was no significant influence of pre-pregnancy BMI ( $r=-0.0010, p=0.8517$ ) or $\mathrm{BMI}$ at the time of delivery $(r=0.0044, p=0.4146)$ on the occurrence of IUGR's.

During the study period, there was a significant increase in the births of children with macrosomia and IUGR (Figure 1). The amount of macrosomic newborns increased from 138 cases in year 2006 to 237 cases in year 2014. The amount of IUGR babies increased from 99 cases in the year 2006 to 169 cases in the year 2014.

The weight gain during pregnancy also showed a statistically significant correlation with regard to macrosomic neonates. A higher weight gain was associated with an increased risk of macrosomia ( $r=0.009, p$ $=0.04)$. However, the risk of IUGR neonates was not significantly altered with regard to the weight gain ( $r=$ $-0.010, p=0.06)$.

\section{Discussion}
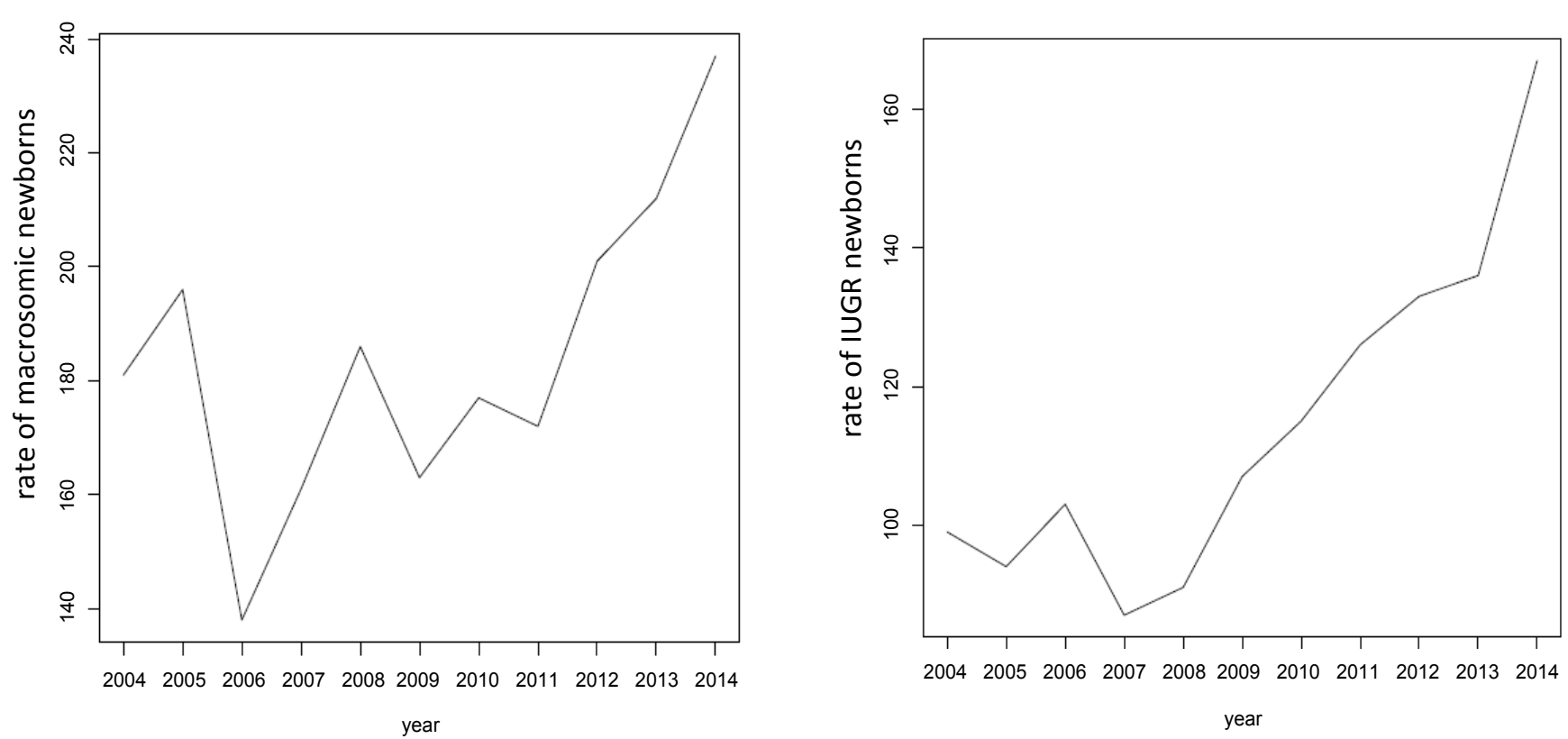

Figure 1: Rate of macrosomic and IUGR newborns during the period of 2004-2014. 
Obesity is one of the biggest epidemics in the $21^{\text {st }}$ century. $35.5 \%$ of the female population living in the United States are obese and $68 \%$ are overweight, whereas $41.4 \%$ of the German population are classified as overweight or obese [21]. In England, adult obesity rose from $16.4 \%$ to $26 \%$ between 1995 and 2010 [22]. Approximately $13.8 \%$ of the worldwide female population is considered as obese [23].

The KiGGS-study evaluated the maternal weight gain in the German population and demonstrated an average increase of maternal weight gain of $2 \mathrm{~kg}$ within the last two decades [8]. Our study results show a mean maternal pre-pregnancy BMI of 24.73. The average increase of weight gain during pregnancy was $13.9 \mathrm{~kg}$. The mean maternal BMI at the time of birth was 29.74 . In the population we examined, we found that $6.94 \%$ women were underweight, $55.57 \%$ women were of normal weight, $23.52 \%$ women were overweight, and $13.97 \%$ women were obese before pregnancy.

As mentioned in the introduction, in 2009 the IOM released new guidelines regarding appropriate maternal weight gain in pregnancy according to pre-pregnancy BMI [16]. These recommendations have been based on observational studies carried out in the United States. However, recent study results questioned these recommendations, especially in case of overweight and obese pregnant women. Data from the German KiGGSstudy demonstrated an increased risk of children later becoming overweight when born by mothers of normal weight that had a high weight gain during pregnancy. One additional kilo weight gain increases the child's risk of later overweight of? only $1 \%$ [8]. Data from this German population also show that overweight and obese pregnant women with a permitted weight gain, according to the recommendations of IOM, developed on the one hand less preeclampsia and also the rate of elective C-section was lower. But on the other hand the rate of diabetes, preterm delivery, less birth weight and higher perinatal morbidity was higher [8].

Another retrospective observational study draws the conclusion that very obese women with a BMI over $40 / \mathrm{m}^{2}$ have less complication risks like gestational diabetes, maternal hypertension, birth complications, fetal macrosomia as well as subsequent overweight of the child and associated complications in case of weight gain reduction during pregnancy up to $10 \mathrm{~kg}$ [7]. Overall, the evidence is too inconsistent to define exact upper and lower limits for the recommended weight gain during pregnancy, depending on the preconceptional Body Mass Index (BMI). Internationally, there is no consensus on weight gain recommendations in pregnancy, especially for overweight and obese women [7].

These inconsistencies allow doubts on the quality of the present data and question the recommendations by the IOM.

Concludingly, the results of our study show that underweight is associated with a higher amount of second stage C-section but with a lower rate of elective C-section. Adipositas is associated with a lower rate of elective C-section, but there was no significance with regard to the rate of second stage C-section. The higher rate of second stage $\mathrm{C}$-sections in the group of underweight women might be a sign for a higher rate of absolute or relative disproportion, especially, as we have seen a higher rate of macrosomic newborns in underweight women. The low rate of elective C-section in overweight and obese women might be due to cautious recommendation for an elective C-section due to the known risk of higher complication rates in overweight and obese women such as intrapartum surgery complications and wound healing defects afterwards. Maternal obesity is a high-risk situation for mother and child, demanding a higher standard in perinatal care.

Our study demonstrated that a higher BMI is associated with an increased risk of perineal lacerations while the weight gain during pregnancy showed no significant influence. These findings are supported by other studies that found that perinatal complications such as perinatal lacerations are higher in overweight and obese women [24,25].

However, the rate of peripartal complications in women with a high BMI was not increased in this study. This may be due to the fact that these women's deliveries are usually thoroughly planned and conducted by more experienced obstetrical staff as they are considered to be high risk situations.

The data of our study shows that a higher prepregnancy $\mathrm{BMI}$ is associated with an increased risk to develop preeclampsia. Whereas, a higher BMI before delivery was associated with an increased risk of hypertension as well as of preeclampsia whereas the weight gain during pregnancy showed neither a significant influence on the development of preeclampsia or hypertension nor on other maternal diseases.

A review analysis did show that that overweight and obese women benefit from diet and exercising, so that they can reduce weight gain. But these interventions did not reduce the risk of preeclampsia or pregnancy related hypertension [26].

Another study demonstrated a positive correlation between a high BMI before 16 weeks of gestation and the risk of developing preeclampsia in the course of the pregnancy [27].

These results confirm the data in our study. Pre-pregnancy BMI has an impact on the potential development of conditions like preeclampsia. 
Nevertheless, pre-pregnancy conditions influence the developing pregnancy. Studies show that in obese animals' oxidative stress in oocytes and during placentation was increased. Oxidative stress however, may be an important factor in the development of preeclampsia [28].

The risk of preeclampsia is high in obese women compared to non-obese women. Marshall, et al. and Hartge, et al. reported a preeclampsia rate of $10.9 \%$ [29] and $10.1 \%$ [30] in obese women. In our study the overall preeclampsia rate was $2.05 \%$ which is comparable to the prevalence described in literature. However, in our study the rate of preeclampsia in overweight women was $2.03 \%$ and in obese women $2.25 \%$.

In general, the fact that woman's weight at the moment of conception is more important than the weight gain during pregnancy is well accepted [7]. Various studies showed an association between maternal pre-pregnancy obesity as well as excess maternal weight gain during pregnancy and fetal outcome regarding the neonatal, childhood and adult health profile including endocrinological, cardiovascular and neurological issues [31-36].

Other studies suggested less weight gain during pregnancy for obese women to reduce the risk of fetal macrosomia [37-39].

The results of our study present a significant relation between BMI and macrosomia as well as IUGR. Underweight women showed an increased risk of macrosomia and a lower risk of IUGR, while overweight and obese women have an increased risk of macrosomia. The results furthermore displayed that a higher weight gain was associated with a higher rate of macrosomia. The literature $[17,40,41]$ clearly shows a higher risk of macrosomic newborns in overweight and obese women. In contrast to our results, the literature clearly defines a higher risk of IUGR and a lower risk of macrosomia in underweight women [17,42-45].

These contradictory results in literature and in our study might be explained due to the fact that the $\mathrm{BMI}$ is just a measure of the body symmetry. That means that the BMI can be identical in an extremely tall woman and in an extremely short woman if their body mass ratios are the same. Therefore, the recommended gestational weight gain cannot be the same for all women with identical BMI but different weight. Based on their study, Mestrovic, et al. proposed to recalculate BMI change in kilograms depending on maternal height instead of just calculating BMI in kilograms [17].

The optimal weight gain in pregnancy is certainly not easy to estimate. Control and correction of weight gain during pregnancy in both underweight and overweight women seems to improve pregnancy outcome [46,47], but adjusting weight before conception seems to have a major impact.
The maternal BMI is certainly not the only influencing factor for an adverse perinatal outcome. Multivariance analyses has indicated nicotine as an important influential factor for adverse outcomes in case of underweight pregnant women and gestation diabetes in case of overweight [48]. Certainly, the correlation between factors like consumption of nicotine and social status of under- and overweight women plays an important role $[48,49]$. Also, genetic and sociocultural factors should be considered, as a combination of both these factors is most likely influential [50,51].

\section{Limitation of the Study}

We acknowledge the limitations of a retrospective study design from a single institution as well as the low amount of cases in the varying subgroups. However, the strength of this study is the high overall number of cases over a sufficient period of time in a single primary center. Yet, any study on the effects on pregnancy course and on neonatal and maternal complications and outcome is limited by the difficulty of separating all possible cofactors influencing theses outcome parameters.

\section{Conclusion}

Optimal weight gain during pregnancy in relation to maternal pre-pregnancy BMI remains a controversial issue in perinatology and the management of pregnancies. The risk of preeclampsia, hypertension and macrosomia is high in overweight and obese women. Underweight women are also at risk for adverse perinatal outcome.

Although data of this study suggest a minor role of weight gain during pregnancy as previously suspected, one cannot draw definite conclusions from these findings. Many more co-factors need to be considered.

As the BMI is defined as the body mass divided by the square of the body height it has some limitations. It might overestimate body fat in athletes as well as underestimate body fat in persons with a lower muscle portion. Therefore, the recommendable gestational weight gain cannot be the same for all women with identical BMI, depending on different body composition not reflected by the BMI. Therefore, the recommendable individual optimum gestational weight gain depends on pre-pregnancy weight in relation to the height of the women. Given the epidemiological significance of adipositas, further studies, which focus on individual weight gain assessment are certainly needed to specify the best management in pregnancy.

\section{Acknowledgement}

We are grateful for the support of the statistical analysis, which was carried out by Prof. Dr. Sibbertsen and Dr. Bertram from the Institute of Statistics of the Leibniz University Hanover. 


\section{Funding}

No funding.

\section{Disclosure of Interest}

The authors declare no conflict of interest.

\section{References}

1. Stevens GA, Singh GM, Lu Y, Danaei G, Lin JK, et al. (2012) National, regional, and global trends in adult overweight and obesity prevalences. Popul Health Metr 10: 22.

2. Statistisches Bundesamt (2010) Mikrozensus 2009 Fragen zur Gesundheit. Körpermaße der Bevölkerung. Wiesbaden.

3. Callaway LK, Prins JB, Chang AM, Mclntyre HD (2006) The prevalence and impact of overweight and obesity in an Australian obstetric population. Med J Aust 184: 56-59.

4. Flegal KM, Carroll MD, Kit BK, Ogden CL (2012) Prevalence of obesity and trends in the distribution of body mass index among US adults, 1999-2010. JAMA 307: 491-497.

5. Webber L, Divajeva D, Marsh T, McPherson K, Brown M, et al. (2014) The future burden of obesity-related diseases in the 53 WHO European-Region countries and the impact of effective interventions: A modelling study. BMJ Open 4: e004787.

6. World Health Organization (2003) Diet, nutrition and the prevention of chronic diseases. World Health Organ Tech Rep Ser 916: 1-149.

7. Koletzko B, Bauer CP, Bung $P$, Cremer M, Flothkötter $M$, et al. (2012) Ernährung in der Schwangerschaft Handlungsempfehlungen des Netzwerks Gesund ins Leben-Netzwerk Junge Familie. DMW 137: 1309-1314.

8. Bergmann KE, Bergmann RL, Ellert $U$, Dudenhausen JW (2007) Perinatale Einflussfaktoren auf die spätere Gesundheit. Ergebnisse des Kinder und Jugendgesundheitssurveys (KiGGS). Bundesgesundheitsbl - Gesundheitsforsch - Gesundheitsschutz 50: 670-676.

9. Ovesen P, Rasmussen S, Kesmodel U (2011) Effect of prepregnancy maternal overweight and obesity on pregnancy outcome. Obstet Gynecol 118: 305-312.

10. Gaillard R, Steegers EA, Hofman A, Jaddoe VW (2011) Associations of maternal obesity with blood pressure and the risks of gestational hypertensive disorders. The Generation R Study. J Hypertens 29: 937-944.

11. Macdonald-Wallis C, Tilling K, Fraser A, Nelson SM, Lawlor DA (2013) Gestational weight gain as a risk factor for hypertensive disorders of pregnancy. Am J Obstet Gynecol 209: 327 .

12. Margerison Zilko CE, Rehkopf D, Abrams B (2010) Association of maternal gestational weight gain with shortand long-term maternal and child health outcomes. Am J Obstet Gynecol 202: 574.

13. Huda SS, Brodie LE, Sattar N (2010) Obesity in pregnancy: Prevalence and metabolic consequences. Semin Fetal Neonatal Med 15: 70-76.

14. Ruager-Martin R, Hyde M, Modi N (2010) Maternal obesity and infant outcomes. Early Hum Dev 86: 715-722.

15. Bonfig J (2015) Welche Gewichtszunahme ist in der Schwangerschaft normal? Frauenarzt 56: 44-45.

16. Institute of Medicine (2009) Weight gain during pregnancy: reexamining the guidelines. Washington, DC: National
Academies Press 241-262.

17. Mestrovic Z, Roje D, Vulic M, Zec M (2017) Calculation of optimal gestation weight gain on pre-pregnancy underweight women due to body mass index change in relation to mother's height. Arch Gynecol Obstet 295: 8186.

18. Gibbs RS, Karlan BY, Haney AF, Nygaard I (2008) Danforth 's obstetrics and gynecology. (10 ${ }^{\text {th }}$ edn), Lippincott Williams and Wilkins, Philadelphia, 171.

19. Saliha HM, Mbah AK, Alio AP, Clayton HB, Lynch O (2009) Low pre-pregnancy body mass index and risk of medically indicated versus spontaneous preterm singleton birth. Eur J Obstet Gynecol Reprod Biol 1: 119-123.

20. Borkowski W, Mielniczuk H (2007) Preterm delivery in relation to combined pregnancy weight gain and prepregnancy body mass. Przegl Epidemiol 6: 577-584.

21. WHO (2006) Global NCD Infobase. Geneva, Switzerland: World Health Organization.

22. (2011) The NHS Information Centre for Health and Social Care. Health survey for England - 2010: Respiratory health.

23. Dietz PM, Callaghan WM, Morrow B, Cogswell ME (2005) Population-based assessment of the risk of primary cesarean delivery due to excess prepregnancy weight among nulliparous women delivering term infants. Matern Child Health J 9: 237-244.

24. Voldner N, FrØslie KF, Haakstad LA, BØ K, Henriksen $T$ (2009) Birth complications, overweight and physical inactivity. Acta Obstet Gynecol Scand 88: 550-555.

25. Weichert J, Diedrich K, Hartge DR (2011) Materanale Adipositas.Antenatale Risiken und geburtshilfliche Komplikationen. Gynäkologe 44: 872-878.

26. Syngelaki A, Campos MS, Roberge S, Andrade W, Nicolaides KH (2018) Diet and exercise for preeclampsia prevention in overweight and obese pregnant women: systematic review and meta-analysis. J Matern Fetal Neonatal Med 6: 1-7.

27. Bodnar LM, Ness RB, Markovic N, Roberts GM (2005) The risk of preeclampsia rises with increasing prepregnancy body mass index. Ann Epidemiol 15: 475-478.

28. Poston L, Igosheva N, Mistry HD, Seed PT, Shennan $\mathrm{AH}$, et al. (2011) Role of oxidative stress and antioxidant supplementation in pregnancy disorders. Am J Clin Nutr 94: 1980S-1985S.

29. Marshall NE, Guild C, Cheng YW, Caughey AB, Halloran DR (2012) Maternal superobesity and perinatal outcomes. Am J Obstet Gynecol 206: 417.

30. Hartge D, Spiegler J, Schroeer A, Deckwart V, Weichert J (2016) Maternal super-obesity. Arch Gynecol Obstet 293: 987-992.

31. Avci ME, Sanlikan F, Celik M, Avci A, Kocaer M, et al. (2014) Effects of maternal obesity on antenatal, perinatal and neonatal outcomes. J Matern Fetal Neonatal Med 20: $1-13$.

32. Gohir W, Ratcliffe EM, Sloboda DM (2015) Of the bugs that shape us: Maternal obesity, the gut microbiome, and long term disease risk. Pediatr Res 77: 196-204.

33. Heermann WJ, Bian A, Shintani A, Barkin SL (2014) Interaction between maternal prepregnancy body mass index and gestational weight gain shapes infant growth. Acad Pediatr 14: 463-470.

34. Liggins GC, Howie RN (1972) A controlled trial of antepartum 
glucocorticoid treatment for prevention of respiratory distress syndrome in premature infants. Pediatrics 50: 515525.

35. Mathai S, Derralk JGB, Cutfield WS, Dalziel SR, Harding JE, et al. (2013) Increased adiposity in adults born preterm and their children. PLOS one 8: 1-8.

36. Mehta SH, Kerver JM, Sokol RJ, Keating DP, Paneth N (2014) The association between maternal obesity and neurodevelopmental outcome of offspring. J Pediatr 165: 891-893.

37. Cedergren MI (2006) Effects of gestational weight gain and body mass index on obstetric outcome in Sweden. Int $J$ Gynaecol Obstet 9: 269-274.

38. Cedergren MI (2007) Optimal gestational weight gain for body mass index categories. Obstet Gynecol 1: 359-364.

39. Nohr EA, Vaeth M, Baker JL, Sorensen Tla, Olsen J, et al. (2008) Combined associations of prepregnancy body mass index and gestational weight gain with the outcome of pregnancy. American Journal of Clinical Nutrition 8: 17501759.

40. Yu Z, Han S, Zhu J, Sun X, Ji C, et al. (2013) Prepregnancy body mass index in relation to infant birth weight and offspring overweight/obesity: A systematic review and meta-analysis. PLoS One 8: e61627.

41. Stubert J, Reister F, Hartmann S, Janni W (2018) The risks associated with obesity in pregnancy. Dtsch Arztebl Int 115: 276-283.

42. Jeric M, Roje D, Medic N, Strinic T, Mestrovic Z, et al. (2013) Maternal pre-pregnancy underweight and fetal growth in relation to Institute of Medicine recommendations for gestational weight gain. Early Hum Dev 89: 277-281.

43. Trojner Bregar A, Blickstein I, BrzanSimenc G, Jansa V, Verdenik I, et al. (2017) Perinatal advantages and disadvantages of being underweight before pregnancy: $A$ population-based study. Gynecol Obstet Invest 82: 303306.

44. Ehrenberg HM, Dierker L, Milluzzi C, Mercer BM (2003) Low maternal weight, failure to thrive in pregnancy, and adverse pregnancy outcomes. Am J Obstet Gynecol 1: 1726-1730.

45. Doherty DA, Magann EF, Francis J, Morrison JC, Newnham JP (2006) Pre-pregnancy body mass index and pregnancy outcome. Int J Gynaecol Obstet 9: 242-247.

46. Crane JM, White J, Murphy P, Burrage L, Hutchens D (2009) The effect of gestational weight gain by body mass index on maternal and neonatal outcomes. J Obstet Gynaecol Can 3: 28-35.

47. Oken E, Kleinman KP, Belfort M, Hammitt JK, Gillman MW (2009) Associations of gestational weight gain with shortand long-term maternal and child health outcomes. Am J Epidemiol 1: 173-180.

48. Beckmann C (2015) Der Einfluss biomedizinischer, psychosozialer und sozio-ökonomischer Faktoren auf Frühgeburtlichkeit (niedriges Geburtsgewicht)- Eine Fall Kontrollstudie: Inaugural Dissertation Medizinische Fakultät der Universität des Saarlandes.

49. Altenhöner T, Philippi M, Köhler M (2016) The relevance of maternal socioeconomic characteristics for low birth weight - a case-control study. Geburtshilfe Frauenheilkund 76: 248-254.

50. Gaillard R, Felix JF, Duijts L, Jaddoe VW (2014) Childhood consequences of maternal obesity and excessive weight gain during pregnancy. Acta Obstet Gynecol Scand 93: 1085-1089.

51. Kahraman S, Dirice E, De Jesus DF, Hu J, Kulkarni RN (2014) Maternal insulin resistance and transient hyperglycemia impacts the metabolic and endocrine phenotypes of offspring. Am J Physiol Endocrinol Metab 307: E906-E918. 